\title{
Inbreeding, effective population size, and coancestry in the Latxa dairy sheep breed
}

\author{
I. Granado-Tajada, ${ }^{1 *}$ ๑ S. T. Rodríguez-Ramilo, ${ }^{2} \odot$ A. Legarra, ${ }^{2}$ (1) and E. Ugarte ${ }^{1}(0)$ \\ ${ }^{1}$ Department of Animal Production, NEIKER-BRTA, Basque Institute of Agricultural Research and Development, Agrifood Campus of Arkaute s/n, \\ E-01080 Arkaute, Spain \\ ${ }^{2}$ INRAE, UMR 1388 GenPhySE, 31326 Castanet Tolosan, France
}

\begin{abstract}
Traditionally, breeding programs have estimated and managed inbreeding based on pedigree information. The availability of genomic marker panels has made possible new alternatives to achieve more precise estimates, for example in case of missing pedigree. The objective of the present study was to assess and compare, different estimation methods (pedigree-based methodologies, single SNP-based approach (homozygosity) and runs of homozygosity-based method) to analyze the evolution of genetic diversity measured as inbreeding or as coancestry of 3 selected populations of Latxa dairy sheep (Latxa Cara Rubia and Latxa Cara Negra from Euskadi and Navarre). Genomic data came from 972 artificial insemination rams genotyped with the Illumina OvineSNP50 BeadChip (Illumina Inc., San Diego, CA) whose genealogy consisted of 4,484 animals. Inbreeding estimates based on molecular data were more similar between them than compared with those based on pedigree information. However, the SNP-based approach estimations of effective population size differed more, reflecting the sensitivity of effective population size to small changes in the evolution of inbreeding. The 2 Latxa Cara Negra populations showed increases of inbreeding rates with time and effective population sizes between 64 and 103 animals, depending on breed and methodology used. The Latxa Cara Rubia population did not show an increase in inbreeding rate, mainly due to semen importation from the related French population of Manech Tête Rousse. The effective size estimates based on coancestry increase show a higher variability and they are more sensitive to the source of information and the data structure considered. Realized effective population size based on individual increase in inbreeding were in agreement with the previous estimates. Coancestry evolution analysis based on DNA information showed an increase on coancestry during
\end{abstract}

Received October 14, 2019.

Accepted February 3, 2020

*Corresponding author: igranado@neiker.eus the last $10 \mathrm{yr}$ in all breeds, as a consequence of the selection process. Moreover, the increase on coancestry between Latxa Cara Rubia and Manech Tête Rousse was more noticeable between than within each of those breeds.

Key words: inbreeding, coancestry, effective population size, Latxa breed, dairy sheep

\section{INTRODUCTION}

The Latxa is a breed of autochthonous dairy sheep from the Basque Country and Navarre. Three strains are distinguised according to head color: Latxa Cara Rubia (LCR), Latxa Cara Negra from Euskadi (LCNEUS), and Latxa Cara Negra from Navarre (LCNNAF). The breeding program started in 1984 and currently shows consolidated results with an annual genetic gain for milk yield between 3 and $4 \%$, depending on the strain (Ugarte and Legarra, 2003). The breeding program has $25,717,34,077$, and 12,087 adult ewes alive in 2019 for LCNEUS, LCR, and LCNNAF, respectively. Inbreeding is controlled by avoiding matings of relatives (cousins, sibs, and so on) and trying for new males entering the AI center to come from a diversity of paternal origins (Ugarte, 2007). However, a profound analysis of the evolution of inbreeding has not been done in the Latxa breed.

The same breed is located on the other side of the border in France. This breed, named Manech, is also subdivided into 2 strains according to head color: Manech Tête Rousse (MTR) and Manech Tête Noire (MTN), and both breeding programs started in the 1960s (Larroque et al., 2014). Due to geographical proximity and common use of pastures of the Pyrenees Mountains, animal exchanges between both sides of the borderline are customary. Moreover, in the case of LCR, importation of semen from MTR to the Spanish scheme has been systematic since 2010 to take advantage of the breeding program that was started earlier and is currently successful (Larroque et al., 2014). This connection and differences between breeds have been studied before (Ugarte et al., 1996; Legarra et al., 2014) 
and there is a consensus to consider that LCR and MTR are the same breed but separated geographically and with separate breeding schemes. The importation of semen from MTR could have affected the inbreeding in LCR and modified the coancestry relationship between both breeds.

Traditionally, Latxa breeding programs have estimated and managed inbreeding based on pedigree information, mainly by mating control (avoiding mating between close relatives) and by selecting lambs for reproduction center (choosing animals from different families and avoiding siblings). The inbreeding coefficient $(\boldsymbol{F})$ of an individual is defined as the probability that 2 randomly chosen alleles at a homologous locus within an individual are identical by descent (IBD) where all the alleles in the base population are assumed to be different, meaning the alleles are identical because they are passed down from the same copy of a common ancestor (Malécot, 1948). Homozygosity caused by 2 IBD genomic segments is termed autozygosity, as opposed to allozygosity, which is homozygosity produced by alleles that are identical by state (IBS). The $F$ is therefore an estimate of genome-wide autozygosity (Keller et al., 2011). The relationship between allozygosity and autozygosity is, for a biallelic locus, $I B D=\frac{\left(I B S-p^{2}-q^{2}\right)}{1-p^{2}-q^{2}}(\mathrm{Li}$ and Horvitz, 1953; Toro et al., 2011), where $p$ and $q(p+q=1)$ are the allele frequencies on the base population.

However, the pedigree-based inbreeding coefficient $\left(\boldsymbol{F}_{\text {PED }}\right)$ may not be an accurate measure of inbreeding in sheep breeding programs because they have heterogeneous pedigrees with a considerable proportion of unknown pedigree due to uncontrolled natural mating. In the case of Latxa breed, even though in recent years only $10 \%$ of the animals born have both unknown parents, in the complete pedigree an average of $30 \%$ of the animals have both parents unknown. Therefore, taking into account lack of full knowledge of pedigree, as described above, the estimation of inbreeding coefficients based on pedigree will be underestimated. This problem is not new and VanRaden (1992) suggested methods to compensate for missing pedigrees. In addition, pedigree estimates are not perfect due to pedigree errors (Oliehoek and Bijma, 2009), the lack of consideration of Mendelian sampling variation in IBD estimates (Hill and Weir, 2011), as well as due to linkage disequilibrium caused by selection (Forutan et al., 2018). The availability of genomic marker panels has made possible new alternatives to achieve more precise estimates of coancestry, mate assignment, and inbreeding coefficients than using pedigree records (VanRaden, 2008). There are several advantages of genomic $F$ esti- mates over $F_{\mathrm{PED}}$. First, genomic $F$ can potentially estimate the proportion of genome autozygosity directly measuring homozygosity. Furthermore, genomic $F$ can be estimated in wild populations in which pedigree data are hardly available, as well as bringing the possibility to analyze inbreeding across the genome by chromosome or gene regions (Keller et al., 2011).

To take advantage of these benefits, different methods have been developed to assess the effect of an active breeding program on inbreeding through SNP markers (VanRaden, 2008; Curik et al., 2014; Howard et al., 2017). One of the approaches is to estimate inbreeding SNP by SNP $\left(\boldsymbol{F}_{\mathrm{SNP}}\right)$, which is based on Malécot's (1948) definition: the probability that the 2 alleles of one individual are IBS instead of IBD (Caballero and Toro, 2002). Other useful predictors of inbreeding are the runs of homozygosity (ROH), which are continuous stretches of homozygous loci frequently present at genomic regions subjected to high selective pressures. The ROH-based inbreeding $\left(\boldsymbol{F}_{\mathbf{R O H}}\right)$ has been studied in human populations (McQuillan et al., 2008) and in livestock species (Curik et al., 2014; Peripolli et al., 2017), and several studies have reported their high reliability to estimate inbreeding (Ferenčaković et al., 2013; Hammerly et al., 2016; Forutan et al., 2018).

The availability of molecular information has also brought new insights into the estimation of coancestry (half the additive genetic relationship) between and within populations (Álvarez et al., 2005). Coancestry within populations is another parameter that classically has been estimated based on pedigree information. The coefficient of coancestry is useful mainly to plan matings with the least inbreeding, considering that the inbreeding of an individual depends on the coancestry between their parents (Falconer and Mackay, 1996).

Therefore, the objective of the present study was to assess and compare, for the first time in Latxa breeds, different inbreeding and coancestry estimation methods (pedigree-based methodologies, single SNP-based approach, and ROH-based method) to analyze the genetic diversity of 3 populations of Latxa dairy sheep and to study the consequences of genetic selection on inbreeding. Moreover, the effect of French semen importation into LCR scheme was analyzed by the genetic contribution to the current population and the evolution of coancestry in these breeds.

\section{MATERIALS AND METHODS}

\section{Molecular and Pedigree Data}

The molecular information available was from AI rams, genotyped with Illumina OvineSNP50 BeadChip (Illumina Inc., San Diego, CA), which were born be- 
Table 1. Number of genotyped individuals, number of markers, individuals in full and sub-pedigree, equivalent number of complete generations of full genealogy, and generation interval of full genealogy for Latxa Cara Negra from Euskadi (LCNEUS), Latxa Cara Rubia (LCR), and Latxa Cara Negra from Navarre (LCNNAF)

\begin{tabular}{lccccc}
\hline Breed & $\begin{array}{c}\text { Genotyped } \\
\text { rams }\end{array}$ & Markers & $\begin{array}{c}\text { Full } \\
\text { pedigree }\end{array}$ & Sub-pedigree & $\begin{array}{c}\text { Equivalent number } \\
\text { of complete generations }\end{array}$ \\
\hline LCNEUS & 353 & 39,159 & 263,306 & 1,742 & 5.61 \\
LCR & 427 & 38,168 & 150,183 & 1,901 & 4.24 \\
LCNNAF & 192 & 39,373 & 68,714 & 841 & 4.41 \\
interval
\end{tabular}

tween 1996 and 2016. As quality control, animals with call rate $<0.90$ and parent-progeny Mendelian conflicts $(<5 \%)$ were eliminated. For SNP, markers with heritability estimate of gene content $<0.98$ were removed (Forneris et al., 2015), as well as those with call rate $<0.97$, minor allele frequency $<0.05$, monomorphic or located in sexual chromosomes. Starting from the full pedigree, a sub-pedigree was generated with all known ancestors of the genotyped animals in each breed. Details about each population, the characterization of the pedigree (calculated with the software PEDIG by Boichard, 2002), and the evolution of knowledge of pedigree are shown in Table 1 and Figure 1, respectively. Regarding MTR introgressed animals, the identification of animals and their genealogical information is included into the LCR pedigree. The genomic information of the genotyped MTR rams present in the LCR pedigree was also considered.

\section{Inbreeding, Coancestry, and Effective Population Size Estimates}

The $F_{\mathrm{PED}}$ of genotyped rams were obtained with the program INBUPGF90 from the BLUPF90 family programs (Misztal et al., 2002), using the method published by Aguilar and Misztal (2008) based on the methodology proposed by VanRaden (1992), to calculate inbreeding accounting for missing parents. This method allows estimating inbreeding coefficients in populations with missing genealogy, assuming that the inbreeding coefficients of animals with missing parents are equal to the mean of the inbreeding coefficients of those animals with known parents and born during the same year. Ten iterations were used. Furthermore, pedigree-based inbreeding estimates of the generated sub-pedigree were used to analyze the evolution of mean inbreeding of the Latxa breeds during the last decades.

The inbreeding estimates of genotyped rams based on molecular information were estimated on a SNP by SNP basis (observed homozygosity, or IBS) and from $\mathrm{ROH}$. The inbreeding estimate based on individual SNP $\left(F_{\mathrm{SNP}}\right)$ is the probability that 2 alleles are IBS measured across the genome and was calculated as the proportion of homozygous loci present among the typed genetic markers for each individual (Silió et al., 2013).

The inbreeding estimate based on $\mathrm{ROH}\left(F_{\mathrm{ROH}}\right)$, was measured as the proportion of the genome that is contained in the ROH segments (McQuillan et al., 2008), calculated as

$$
F_{R O H_{i}}=\frac{\sum_{k=1}^{n_{R O H}} l_{R O H_{i k}}}{l_{g}},
$$

where $n_{R O H i}$ is the total number of $\mathrm{ROH}$ in individual $i$, $l_{\text {ROHik }}$ is the length of the $k \mathrm{ROH}$ in individual $i$ in base pairs, and $l_{g}$ is the total length of the genome in base pairs. The criteria established to define a $\mathrm{ROH}$ were as follows: the minimum length that constituted a $\mathrm{ROH}$ was $4 \mathrm{Mb}$, the minimum number of SNP was 30, the minimum density was 1 SNP per $100 \mathrm{~Kb}$, the maximum distance allowed between 2 consecutive homozygous $\mathrm{SNP}$ in a run was $1 \mathrm{Mb}$, and a maximum of 2 missing genotypes and 1 heterozygous genotype within a particular $\mathrm{ROH}$ were permitted. The same criteria were used by Rodríguez-Ramilo et al. (2019) in the study done on the genetically close Manech breed.

The expected heterozygosity (Nei, 1973) is equivalent to the classical Malécot (1948) coefficient of coancestry (Caballero and Toro, 2002) and can be applied either to genealogical coancestry coming from pedigree information or to molecular coancestry measured from markers.

Pedigree-based coancestry $\left(f_{\text {PED }}\right)$ coefficients for the genotyped individuals were calculated based on subpedigree information. Estimates were obtained using the software PEDIG (Boichard, 2002) with the option that implements the algorithm of Meuwissen and Luo (1992).

With molecular markers, the molecular coancestry between individuals $i$ and $j\left(\boldsymbol{f}_{\mathbf{S N P} i j}\right)$ was estimated using Malécot's definition as the probability that 2 alleles drawn at random from each individual are IBS:

$$
f_{S N P_{i j}}=\sum_{k=1}^{n_{S N P}}\left(I_{11, k}+I_{12, k}+I_{21, k}+I_{22, k}\right) / 4 n_{S N P},
$$



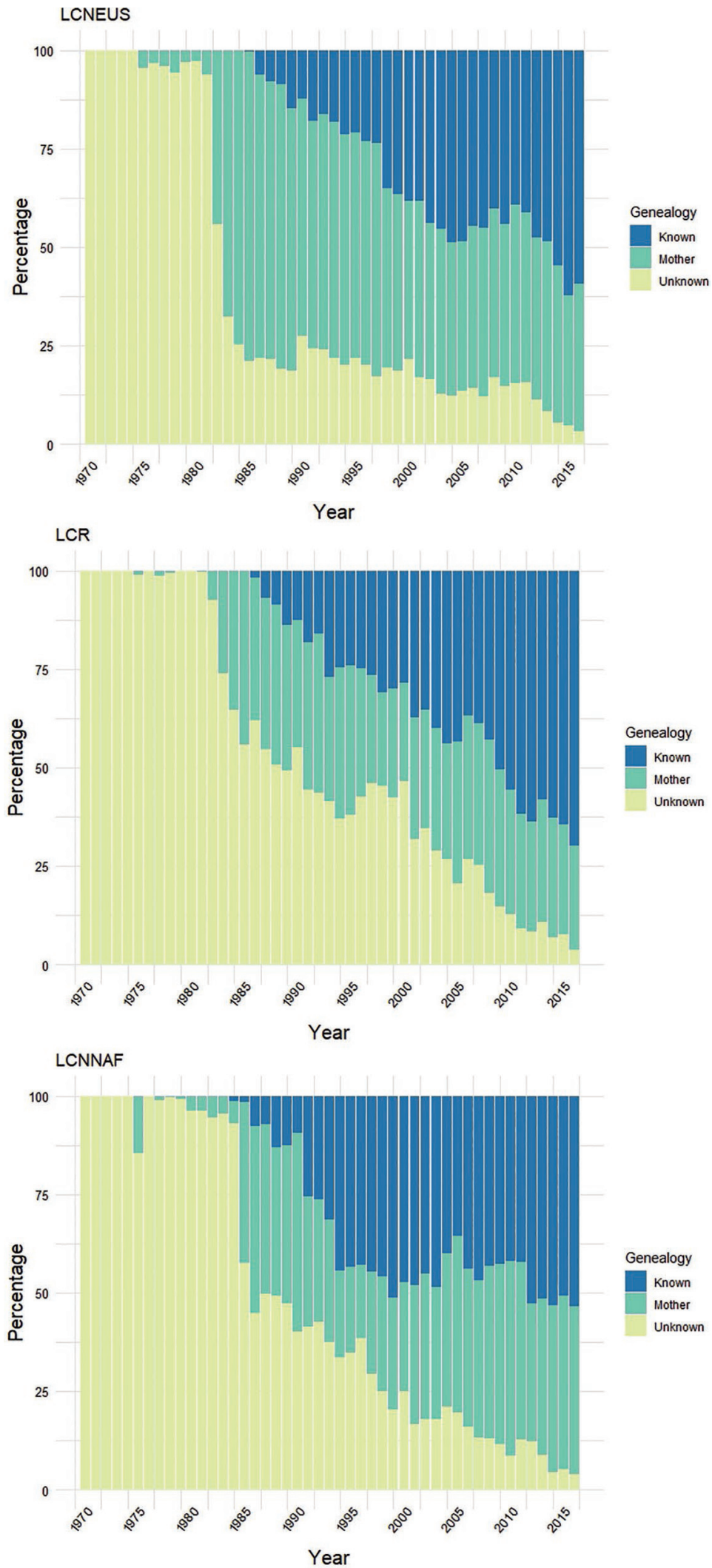

Figure 1. Evolution of known genealogy percentage by individual's year of birth, distinguishing when both parents are known (Known), only mother is known (Mother), and both parents are unknown (Unknown) for Latxa Cara Negra from Euskadi (LCNEUS), Latxa Cara Rubia (LCR), and Latxa Cara Negra from Navarre (LCNNAF). 
where $n_{S N P}$ is the total number of SNP, and $I_{x y, k}$ is an indicator variable that is 1 when both alleles of an individual in the SNP $k$ are equal and 0 if they are not equal. It can be noted that $F_{S N P_{i}}=2 f_{S N P i i}-1$ (Caballero and Toro, 2002).

Rates of inbreeding per year of pedigree and genomicbased estimations were calculated as the regression coefficient of the inbreeding on the year of birth, considering in all cases only the inbreeding estimates of genotyped individuals. Then, the effective population size $\left(\boldsymbol{N}_{e}\right)$ was calculated by $N_{e}=1 / 2 \Delta F$ (Falconer and Mackay, 1996), where $\Delta F$ represents the rate of inbreeding per year multiplied by the generation interval. Approximated estimations of confidence intervals for $N_{e}$ were obtained from the standard error of the rates of inbreeding per year. The same procedure was applied to calculate $N_{e}$ based on pedigree and molecular coancestry estimates.

In addition, realized effective population size $\left(\overline{N_{e}}\right)$ estimates were calculated using ENDOG software (version v4.8; Gutiérrez and Goyache, 2005). These estimates were based on individual increase in inbreeding $\left(\Delta F_{i}\right)$ and its equivalent individual increase in coancestry $\left(\Delta f_{i}\right)$, obtained from pedigree information (Cervantes et al., 2008, 2011; Gutiérrez et al., 2009).

\section{Contribution of Founders and Evolution of Coancestry}

To analyze the effect of historical importation of semen from French MTR into Spanish LCR, and to assess how that importation has affected the current population, the contribution of MTR to LCR population and its evolution were studied.

Considering pedigree information of LCR, which includes introgressed MTR individuals and their genealogy, the contribution of founders of each breed to the current population was estimated with the program ENDOG (version v4.8; Gutiérrez and Goyache, 2005), based on the average relatedness coefficient of each individual. In this case, there is no correction for missing pedigree, so that there is an underestimation of average coancestry.

Additionally, another estimate of the introgression of MTR into LCR was obtained by analyzing the population structure based on genomic information. The software STRUCTURE (version 2.3.4; Pritchard et al., 2000) was used, with a model-based clustering algorithm and considering a subset of 19,084 SNP, by selecting every second marker of 427 LCR and 106 MTR individuals. The admixture model was employed, considering allele frequencies to be correlated between populations (Falush et al., 2003). A burn-in period of 10,000, 50,000 Markov chain Monte Carlo repeats, and 2 genetic clusters were used.

Moreover, taking into account the molecular coancestry $\left(f_{\text {SNP }}\right)$ estimates of genotyped rams (calculated as previously described), the coancestry within each population and between LCR and MTR was analyzed. In addition, the evolution of average coancestry within and between these breeds during the last decade was analyzed comparing old and current rams, selecting the $25 \%$ of the oldest and the $25 \%$ of the youngest genotyped rams as described in Table 2 .

\section{RESULTS AND DISCUSSION}

\section{Inbreeding, Coancestry, and Effective Population Size Estimates}

Average inbreeding values for the genotyped AI rams of the studied breeds are shown in Table 3. The SNPby-SNP based inbreeding estimates $\left(F_{\mathrm{SNP}}\right)$ were higher $(0.6110 \pm 0.0005$ for LCNEUS $)$ than those obtained with other methodologies because $F_{\mathrm{SNP}}$ does not distinguish between IBS and IBD. The difference is a constant and therefore irrelevant when the rate of increase of inbreeding per generation is calculated (Toro et al., 2011), which is actually a more relevant parameter (e.g., Howard et al., 2017). Pedigree and ROH-based inbreeding estimates of the genotyped animals showed average inbreeding values in the more usual scale of $\mathrm{IBD}\left(F_{\mathrm{PED}} 0.0183 \pm 0.0012\right.$ and $F_{\mathrm{ROH}} 0.0333 \pm 0.0012$

Table 2. Distribution of genotyped rams across old and current categories and year of birth for Latxa Cara Negra from Euskadi (LCNEUS), Latxa Cara Rubia (LCR), Latxa Cara Negra from Navarre (LCNNAF), and Manech Tête Rousse (MTR)

\begin{tabular}{lcccccc}
\hline & & \multicolumn{2}{c}{ Old rams } & & \multicolumn{2}{c}{ Current rams } \\
\cline { 3 - 4 } \cline { 6 - 7 } Breed & $\begin{array}{c}\text { Genotyped } \\
\text { rams }\end{array}$ & No. & Year of birth & & No. & Year of birth \\
\hline LCNEUS & 353 & 98 & $1997-2005$ & & 96 & $2014-2016$ \\
LCR & 427 & 96 & $1998-2005$ & & 97 & $2014-2016$ \\
LCNNAF & 192 & 29 & $1996-2004$ & & 33 & $2013-2016$ \\
MTR & 106 & 21 & $1999-2001$ & & 24 & $2009-2013$ \\
\hline
\end{tabular}


Table 3. Mean inbreeding $(F) \pm \mathrm{SE}$ and rate of inbreeding per generation $(\Delta F) \pm \mathrm{SE}$; calculated with sub-pedigree information (PED), SNP by SNP (SNP), and runs of homozygosity $(\mathrm{ROH})$ for Latxa Cara Negra from Euskadi (LCNEUS), Latxa Cara Rubia (LCR), and Latxa Cara Negra from Navarre (LCNNAF)

\begin{tabular}{|c|c|c|c|c|}
\hline Parameter & Method & \multicolumn{3}{|c|}{ Breed } \\
\hline$F$ mean $\pm \mathrm{SE}$ & $\begin{array}{l}F_{\mathrm{PED}} \\
F_{\mathrm{SNP}} \\
F_{\mathrm{ROH}} \\
\Delta F_{\mathrm{PED}} \\
\Delta F_{\mathrm{SNP}} \\
\Delta F_{\mathrm{ROH}}\end{array}$ & $\begin{array}{l}0.0183 \pm 0.0012 \\
0.6110 \pm 0.0005 \\
0.0333 \pm 0.0012 \\
0.0079 \pm 0.0009 \\
0.0012 \pm 0.0004 \\
0.0054 \pm 0.0010\end{array}$ & $\begin{aligned} 0.0159 & \pm 0.0004 \\
0.6076 & \pm 0.0004 \\
0.0268 & \pm 0.0009 \\
0.0022 & \pm 0.0004 \\
-0.0001 & \pm 0.0004 \\
0.0007 & \pm 0.0009\end{aligned}$ & $\begin{array}{l}0.0184 \pm 0.0012 \\
0.6165 \pm 0.0008 \\
0.0335 \pm 0.0017 \\
0.0073 \pm 0.0012 \\
0.0022 \pm 0.0009 \\
0.0049 \pm 0.0018\end{array}$ \\
\hline
\end{tabular}

for LCNEUS), with ROH-based estimates $\left(F_{\mathrm{ROH}}\right)$ being higher in all breeds. Mean inbreeding estimates considering all the individuals in pedigree are lower $(0.0037 \pm 0.0001$ for LCNEUS) than current results (Granado-Tajada et al., 2019), as would be expected due to missing genealogy.

The correlation coefficients between inbreeding estimates of genotyped rams are shown in Table 4 . For the 3 breeds, the correlations between estimates based on molecular information were high $(0.84,0.84$, and 0.87 for LCNEUS, LCR, and LCNNAF, respectively) and moderate-low between estimations based on pedigree and molecular data (0.40 and 0.28, 0.27 and 0.25 , and 0.48 and 0.46 for $\mathrm{ROH}$ and SNP-based estimations for LCNEUS, LCR, and LCNNAF, respectively).

Inbreeding estimates in the Manech Tête Noire and Tête Rousse (LCN and LCR equivalent breeds at France) were done with the same methodologies and reported slightly higher means (e.g., mean $F_{\mathrm{ROH}} 0.0440$ and 0.0368 for MTN and MTR, respectively), possibly linked with the fact that they have deeper and more complete genealogy (Rodríguez-Ramilo et al., 2019). Also identical criteria were used to define a $\mathrm{ROH}$ and estimate inbreeding in the Spanish Holstein population, which showed a much higher mean $F_{\mathrm{ROH}}$ of 0.0770 (Rodríguez-Ramilo et al., 2015), as could be expected in dairy cattle due to stronger selection pressure.

Several studies have shown that characterizing inbreeding based on $\mathrm{ROH}$ provides a better measure of

Table 4. Correlation coefficients of inbreeding estimates of genotyped rams, calculated based on sub-pedigree information $\left(F_{\mathrm{PED}}\right)$, SNP by SNP $\left(F_{\mathrm{SNP}}\right)$, and runs of homozygosity $\left(F_{\mathrm{ROH}}\right)$ for Latxa Cara Negra from Euskadi (LCNEUS), Latxa Cara Rubia (LCR), and Latxa Cara Negra from Navarre (LCNNAF)

\begin{tabular}{lccc}
\hline & \multicolumn{3}{c}{ Breed } \\
\cline { 2 - 4 } Item & LCNEUS & LCR & LCNNAF \\
\hline$F_{\mathrm{PED}}-F_{\mathrm{SNP}}$ & 0.28 & 0.25 & 0.46 \\
$F_{\mathrm{PED}}-F_{\mathrm{ROH}}$ & 0.40 & 0.27 & 0.48 \\
$F_{\mathrm{SNP}}-F_{\mathrm{ROH}}$ & 0.84 & 0.84 & 0.87 \\
\hline
\end{tabular}

individual inbreeding than using pedigree information (e.g., Ferenčaković et al., 2013 or Forutan et al., 2018) and $F_{\mathrm{ROH}}$ have been widely studied in different livestock species (Peripolli et al., 2017). However, there is not an established, consistent, and reproducible criterion, which makes comparisons between studies challenging (Peripolli et al., 2017). Defining different minimum length of $\mathrm{ROH}$ is analogous to changing the depth of pedigree; shorter $\mathrm{ROH}$ display more ancient inbreeding due to recombination events as a function of the number of generations. However, longer $\mathrm{ROH}$ show more recent inbreeding because the probability of breaking up IBD segments from recombination is reduced (Curik et al., 2014). In the same way, all the criteria needed to define a $\mathrm{ROH}$ will affect the estimated ROH-based inbreeding $\left(F_{\mathrm{ROH}}\right)$. On this matter, Rodríguez-Ramilo et al. (2019) have analyzed the effect of 6 parameters to establish suitable criteria to define a $\mathrm{ROH}$, based on Manech sheep data. They found that the minimum $\mathrm{ROH}$ length, the minimum number of SNP that constituted a $\mathrm{ROH}$, as well as the minimum density and the maximum distance between 2 homozygous SNP, are $\mathrm{ROH}$-defining factors with important implications in the estimation of the rate of inbreeding. However, inbreeding estimates do not change much unless extreme values are considered.

The rate of inbreeding per generation $(\Delta F)$ of genotyped rams followed a similar pattern as the mean inbreeding (Table 3), with pedigree-based estimates close to ROH-based ones $(0.0079 \pm 0.0009$ and 0.0054 \pm 0.0010 respectively, for LCNEUS) and higher than SNP-based estimates (0.0012 \pm 0.0004 for LCNEUS), which were lower in all breeds. These $\Delta F$ are in agreement with those considered as admissible by Sonesson et al. (2012) when they analyzed the balance between genetic gain and inbreeding increase, which may indicate that there has been a suitable mating control and selection of AI rams. These results were consistent for LCN populations, but LCR showed low or almost zero rates $\left(\Delta F_{\mathrm{SNP}}-0.0001 \pm 0.0004\right)$. Figure 2 shows the inbreeding evolution of Latxa populations 


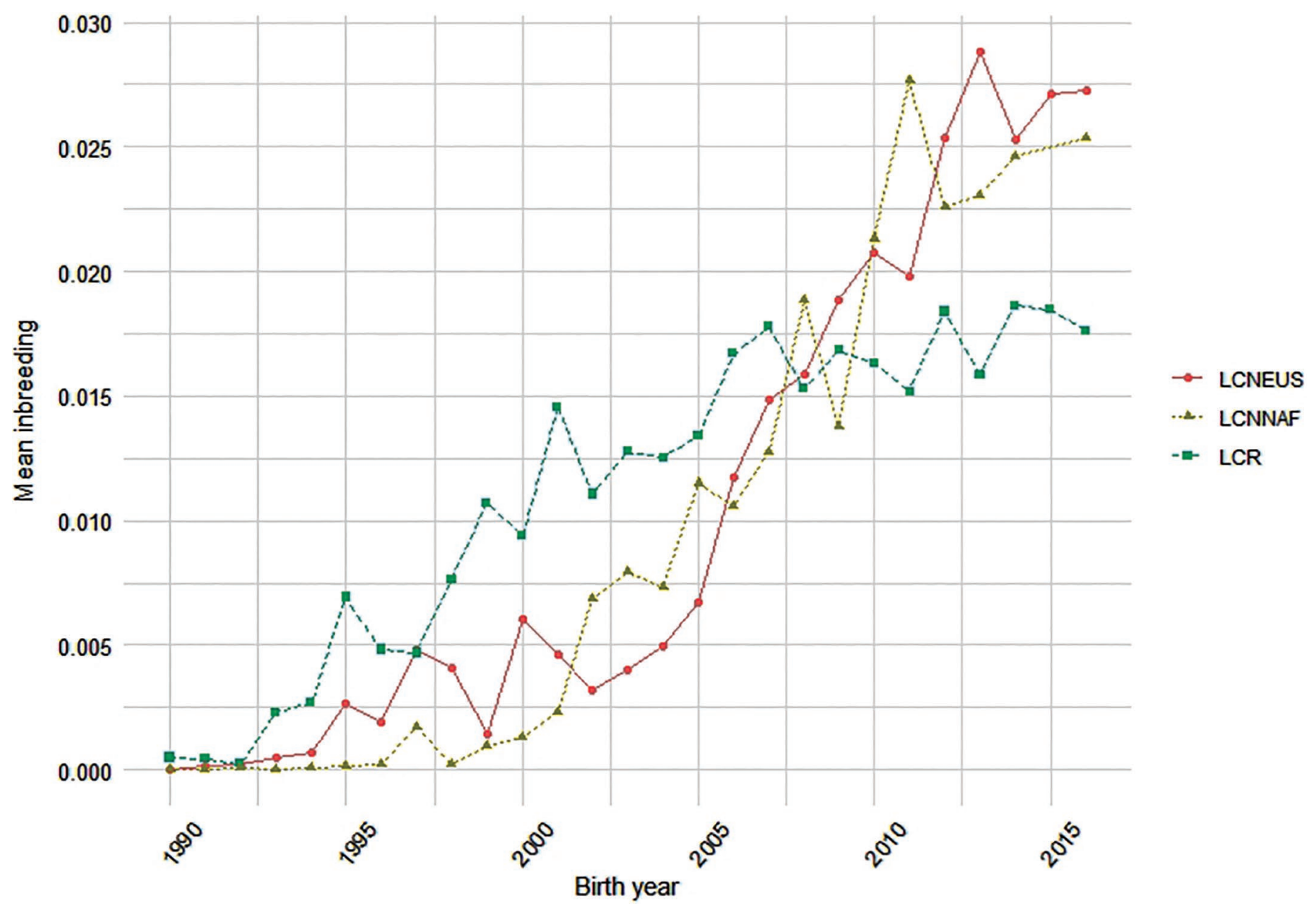

Figure 2. Evolution of inbreeding based on sub-pedigree data for Latxa Cara Negra from Euskadi (LCNEUS), Latxa Cara Rubia (LCR), and Latxa Cara Negra from Navarre (LCNNAF).

based on sub-pedigree information. Overall, the trend has been to increase, with differences between black and red populations. Both LCN populations showed a more noticeable increase from 2000 until now, whereas LCR inbreeding was rising since the 1990s to the end of 2000 s, when it arrived at a plateau. This could be due to historical importation of semen and the systematic importation during the last $10 \mathrm{yr}$ from the French MTR.

Effective population sizes are shown in Table 5 (in LCR breed, as the $F$ increase per generation based on molecular data was almost zero, no estimates of $N_{e}$ could be made). In the case of LCN breeds, $N_{e}$ estimates were lower when pedigree data were used (64 and 69 for LCNEUS and LCNNAF, respectively) and slightly higher in ROH-based ones (93 and 103 for LCNEUS and LCNNAF, respectively). The $N_{e}$ calculated with pedigree-based inbreeding coefficients of all the individuals in pedigree brings the highest estimates (288, 254, and 213 for LCNEUS, LCR, and LCNNAF, respectively; Granado-Tajada et al., 2019), but we have to keep in mind the effect of the missing genealogy that is only partially corrected using the method of VanRaden (1992). The SNP-based inbreeding estimates also showed high $N_{e}$ (420 and 227 for LCNEUS and LCNNAF, respectively) but with large confidence intervals. Comparing methodologies, Rodríguez-Ramilo et al. (2019) reported similar results in related breeds, with pedigree and ROH-based $N_{e}$ being smaller than SNP-based results. Rodríguez-Ramilo et al. (2019) found that the difference depends on the criteria used to define a $\mathrm{ROH}$, and as soon as more genomic information is considered, the $N_{e}$ estimates are more homogeneous and confidence intervals become more adjusted.

The estimated $N_{e}$ based on inbreeding showed that, in spite of different population sizes, LCNEUS and LCNNAF have similar effective population sizes, reflecting the importance of the management done at the AI center to keep genetic variability. Nevertheless, it must be considered that our analysis was based on 
the available molecular information, which comes only from AI rams, which do not represent the whole population of rams contributing to the population. Hence, it would be necessary to continue completing the information to have a more representative sample of the real population and more accurate effective population size estimates.

The results are in agreement with the estimated population sizes for other sheep breeds with similar characteristics such as Manech Tête Noire (for which $N_{e}$ was 53,179 , and 81 based on $F_{\mathrm{PED}}, F_{\mathrm{SNP}}$, and $F_{\mathrm{ROH}}$, respectively) or Basco-Béarnaise (estimated $N_{e}$ of 51 , 114 , and 59 based on $F_{\mathrm{PED}}, F_{\mathrm{SNP}}$, and $F_{\mathrm{ROH}}$, respectively) defined with the same criteria as the present study (Rodríguez-Ramilo et al., 2019). For the Churra dairy sheep breed similar results were also found $\left(N_{e}\right.$ $=83$ ) by Chitneedi et al. (2017). Other studies have reported effective population sizes between 88 and 1,317 in different milk and meat sheep breeds, which were calculated using linkage disequilibrium estimates (Kijas et al., 2012; Al-Mamun et al., 2015; Beynon et al., 2015) so they are not fully comparable.

Differences between results depending on the applied methodology are expected, given that each inbreeding coefficient is defined in relation to a different base population. In this study, $F_{\mathrm{PED}}$ is relative to the pedigreedepth; $F_{\mathrm{SNP}}$ is dependent on Hardy-Weinberg equilibrium and the set of loci included in the SNP chip, and $F_{\mathrm{ROH}}$ is relative to the $\mathrm{ROH}$ length (Rodríguez-Ramilo et al., 2019). Even though pedigree information has been traditionally used to manage inbreeding (Sonesson et al., 2012), different studies have reported that IBD proportion is better predicted by a large number of genetic markers (Li et al., 2011; Kardos et al., 2015).

Calculations of the effective population size based on coancestry coefficients from sub-pedigree information as well as SNP-by-SNP were also performed (Table 5). The obtained results indicate agreement between $N_{e}$ estimates using $f_{\mathrm{PED}}$ and $f_{\mathrm{SNP}}$. However, for LCNNAF the $N_{e}$ estimations were negative due to no increase in coancestry (Gutiérrez et al., 2008). Possibly, this is due to the unbalanced number of genotyped animals per year (e.g., 9 animals born in 2005 and 67 animals born in 2010). In some cases, to estimate the coancestry between animals of the same year of birth there are few animals and not many coancestry estimates. Results from pedigree indicate that estimates of effective population size obtained from coancestry were higher than estimates obtained from inbreeding, suggesting that matings between relatives are being performed. This is probably due to assortative mating of elite sires and dams to generate elite males, even if the mating of animals with any common grandparent is avoided. However, results obtained from SNP-by-SNP do not support this statement.

The estimates of the realized effective population size based on individual increase in inbreeding and in coancestry from sub-pedigree information are also shown in Table 5. The $\overline{N_{e}}$ results obtained from $\overline{\Delta F_{i}}$ were in agreement with the estimates based on $\Delta F_{P E D}$ and $\Delta F_{R O H}$. The $\overline{N_{e}}$ results obtained from $\overline{\Delta f}$ were different and the lowest among all the computed estimates. Other studies also showed different $N_{e}$ estimates according to the applied methodology [e.g., the realized effective population size for the Corse dairy sheep breed was 675 based on $\overline{\Delta F_{i}}$ and 220 based on $\overline{\Delta f_{i}}$ (Leroy et al., 2013)].

It should be considered that the obtained $N_{e}$ and $\overline{N_{e}}$ estimates are likely to be conditioned by the small reference population size and the unbalanced number of genotyped individuals per year, which limits the amount of information taken into account.

Table 5. Effective population size $\left(N_{e}\right)$ estimates with $95 \%$ CI for the genotyped rams and realized effective size $\left(\overline{N_{e}}\right) \pm$ SE; calculated with sub-pedigree information (PED), SNP by SNP (SNP), and runs of homozygosity (ROH); based on inbreeding rate per generation $(\Delta F)$, coancestry rate per generation $(\Delta f)$, individual increase in inbreeding $\left(\overline{\Delta F_{i}}\right)$, and individual increase in coancestry $\left(\overline{\Delta f_{i}}\right)$ for Latxa Cara Negra from Euskadi (LCNEUS), Latxa Cara Rubia (LCR), and Latxa Cara Negra from Navarre (LCNNAF)

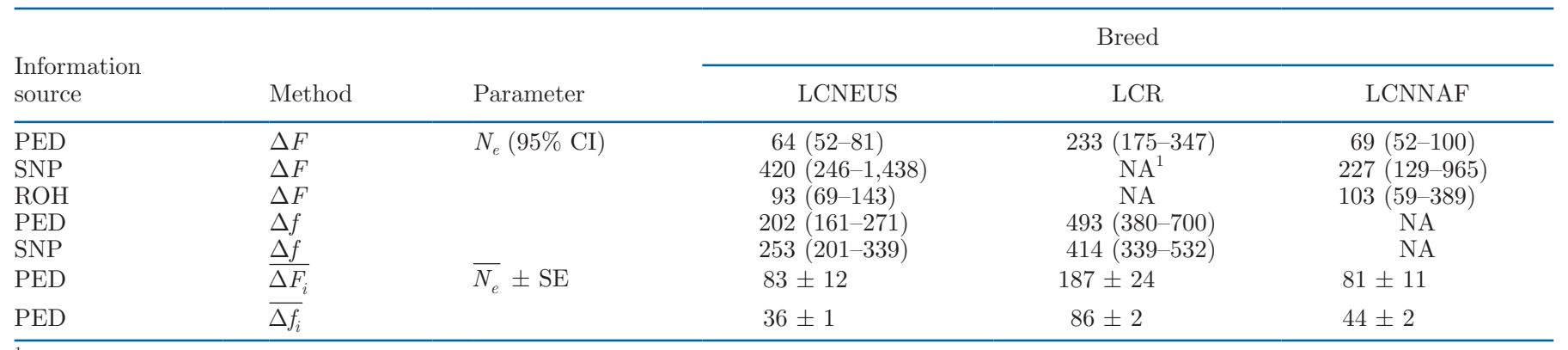

${ }^{1} \mathrm{NA}=$ not available. 

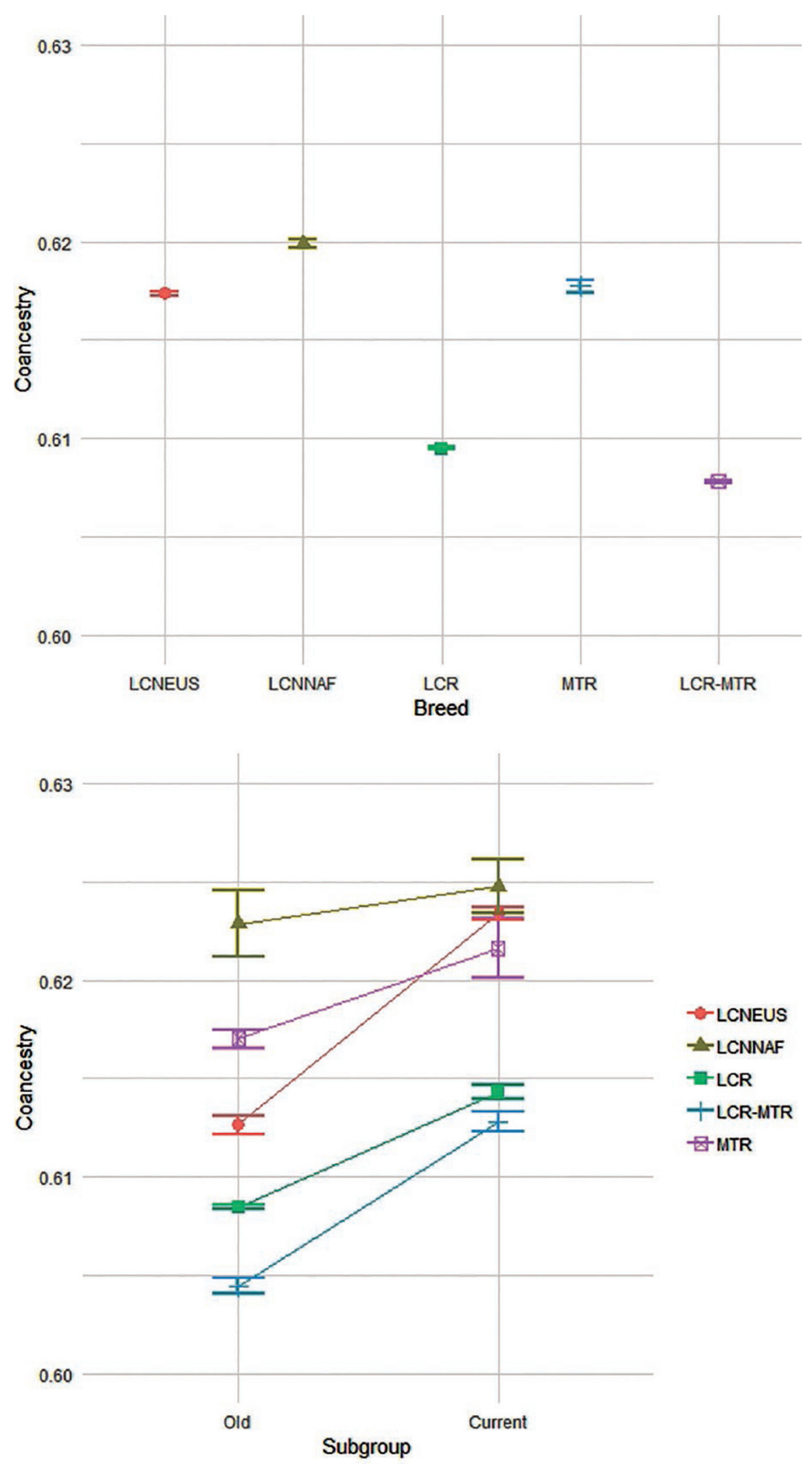

Figure 3. Coancestry within Latxa Cara Negra from Euskadi (LCNEUS), Latxa Cara Negra from Navarre (LCNNAF), Latxa Cara Rubia (LCR), and Manech Tête Rousse (MTR) breeds, and between LCR and MTR breeds. (A) Considering all genotyped rams and (B) considering old and current rams. Bars indicate $95 \%$ CI. 


\section{Contribution of Founders and Evolution of Coancestry}

After 10 yr of systematic semen importation, the coancestry study based on pedigree information reported that MTR individuals represent one-third (0.3266 \pm 0.0021 ) of LCR population founder individuals, whereas LCR individuals are the principal contributors of the current population $(0.6734 \pm 0.0001)$. So the effect of French males used historically has been noteworthy and is reflected into the genetics of the current population. However, it must be considered that pedigree information reflects the vast majority of MTR rams used because current importation is done by AI, whereas the contribution of Latxa natural mating rams gets lost in most cases due to it not being registered and non-systematic paternal filiations being done afterward. Therefore, the contribution of Latxa rams to the current population is likely underestimated.

Regarding the admixture proportion estimates based on genomic information, similar results were found. The LCR individuals showed a small proportion of MTR ancestry (0.3989 \pm 0.0108$)$, whereas the main ancestry corresponded to the LCR genetic cluster (0.6011 $\pm 0.0108)$. The results show a slightly higher effect of MTR into LCR genetics than based on pedigree information, although as a different source of information was considered, it is not directly comparable.

Additionally, the available molecular information allowed us to calculate the coancestry within breeds and between MTR and LCR breeds. Figure 3A shows that average coancestry across MTR males used in LCR was higher $(0.6177 \pm 0.0003)$ than across LCR males $(0.6095 \pm 0.0001)$. The coancestry across the 2 breeds, as we could guess, was lower $(0.6078 \pm 0.0001)$. Regarding the black populations, coancestry was higher than within the LCR breed and similar within MTR $(0.6174 \pm 0.0001$ and $0.6199 \pm 0.0002$ for LCNEUS and LCNNAF, respectively). However, if the evolution of this parameter between old and current genotyped rams is considered (Figure 3B), it can be observed that the increase of coancestry between LCR and MTR after around $10 \mathrm{yr}$ is more marked (0.0084) than the increase within each population $(0.0058,0.0046$, and 0.0019 for LCR, MTR, and LCNNAF, respectively). The only population with a higher increase in coancestry was LCNNEUS (0.0108), possibly due to being a closed population with no importation of semen from French breeding programs, in contrast to LCR.

As time goes by, coancestry will continue increasing, so if the systematic importation of semen continues, in the future Latxa and Manech red populations will likely be genetically more similar and closer.

\section{CONCLUSIONS}

We have shown the genetic diversity available in the Latxa population. There are appreciable differences between estimates based on genealogy and molecular data, and also the applied methodology. When the proportion of homozygous SNP is used to estimate effective population size, results differ more than with the other methods. This confirms what other authors suggested about the sensitivity of proportion of homozygous SNP methodology when the molecular data are limited. Hence, molecular data are useful to infer inbreeding when pedigree information is not complete or deep enough and makes it possible to obtain more precise inbreeding and $N_{e}$ estimates. The effective population size estimates based on coancestry increase show a higher variability and are more sensitive to the source of information and the data structure considered. Considering the evolution of the Latxa breeding program, the current inbreeding increase is moderate. Taking into account $F$ and $N_{e}$ estimates based on pedigree and $\mathrm{ROH}$ from the available and genotyped AI rams, it seems that there has been a suitable mating control and selection of lambs for AI, even though decisions were taken considering pedigree-based inbreeding estimates. Moreover, if systematic importation French semen continues, Latxa and Manech red strains will be genetically closer. Therefore, it is necessary to continue controlling inbreeding to avoid reaching undesirable levels, and with this goal, molecular information gives us a new tool that allows a more accurate monitoring of inbreeding and Manech influence.

\section{ACKNOWLEDGMENTS}

Thanks go to the Confederación de Asociaciones de Criadores de Ovino de Razas Latxa y Carranzana. Vitoria-Gasteiz (Spain): Programa INTERREG V-A España-Francia-Andorra (POCTEFA; https://www .poctefa.eu/) for providing the pedigree data; to the Department of Economic Development and Infrastructure of the Basque Government for the grant for young researchers and technologists; and to POCTEFA for financing the project Ardi Research Development and Investigation (ARDI; EFA208/16) with European Union Fonds Européen de Développement Régional (FEDER). The authors have not stated any conflicts of interest.

\section{REFERENCES}

Aguilar, I., and I. Misztal. 2008. Technical note: Recursive algorithm for inbreeding coefficients assuming nonzero inbreeding of un- 
known parents. J. Dairy Sci. 91:1669-1672. https://doi.org/10 $.3168 /$ jds.2007-0575.

Al-Mamun, H. A., S. A. Clark, P. Kwan, and C. Gondro. 2015. Genome-wide linkage disequilibrium and genetic diversity in five populations of Australian domestic sheep. Genet. Sel. Evol. 47:90-104. https://doi.org/10.1186/s12711-015-0169-6.

Álvarez, I., J. P. Gutiérrez, L. J. Royo, I. Fernández, E. Gómez, J. J. Arranz, and F. Goyache. 2005. Testing the usefulness of the molecular coancestry information to assess genetic relationships in livestock using a set of Spanish sheep breeds. J. Anim. Sci. 83:737-744. https://doi.org/10.2527/2005.834737x.

Beynon, S. E., G. T. Slavov, M. Farre, B. Sunduimijid, K. Waddams, B. Davies, W. Haresign, J. Kijas, I. M. MacLeod, C. J. Newbold, L. Davies, and D. M. Larkin. 2015. Population structure and history of the Welsh sheep breeds determined by whole genome genotyping. BMC Genet. 16:65. https://doi.org/10.1186/s12863-015 -0216-x.

Boichard, D. 2002. Pedig: A fortran package for pedigree analysis suited to large populations. In 7th World Congress on Genetics Applied to Livestock Production, Montpellier, France.

Caballero, A., and M. A. Toro. 2002. Analysis of genetic diversity for the management of conserved subdivided populations. Conserv. Genet. 3:289-299. https://doi.org/10.1023/A:1019956205473.

Cervantes, I., F. Goyache, A. Molina, M. Valera, and J. P. Gutiérrez. 2008. Application of individual increase in inbreeding to estimate realized effective sizes from real pedigrees. J. Anim. Breed. Genet. 125:301-310. https://doi.org/10.1111/j.1439-0388.2008.00755.x.

Cervantes, I., F. Goyache, A. Molina, M. Valera, and J. P. Gutiérrez. 2011. Estimation of effective population size from the rate of coancestry in pedigreed populations. J. Anim. Breed. Genet. 128:56-63. https://doi.org/10.1111/j.1439-0388.2010.00881.x.

Chitneedi, P., J. J. Arranz, A. Suarez-Vega, E. García-Gámez, and B. Gutiérrez-Gil. 2017. Estimations of linkage disequilibrium, effective population size and $\mathrm{ROH}$-based inbreeding coefficients in Spanish Churra sheep using imputed high-density SNP genotypes. Anim. Genet. 48:436-446. https://doi.org/10.1111/age.12564.

Curik, I., M. Ferenčaković, and J. Sölkner. 2014. Inbreeding and runs of homozygosity: A possible solution to an old problem. Livest. Sci. 166:26-34. https://doi.org/10.1016/j.livsci.2014.05.034.

Falconer, D. S., and T. F. C. Mackay. 1996. Introduction to Quantitative Genetics. Harlow: Longman Scientific \& Technical, New York, NY.

Falush, D., M. Stephens, and J. K. Pritchard. 2003. Inference of population structure using multilocus genotype data: Linked loci and correlated allele frequencies. Genetics 164:1567-1587.

Ferenčaković, M., J. Sölkner, and I. Curik. 2013. Estimating autozygosity from high-throughput information: Effects of SNP density and genotyping errors. Genet. Sel. Evol. 45:42. https://doi.org/10 $.1186 / 1297-9686-45-42$.

Forneris, N. S., A. Legarra, Z. G. Vitezica, S. Tsuruta, I. Aguilar, I. Misztal, and R. J. C. Cantet. 2015. Quality control of genotypes using heritability estimates of gene content at the marker. Genetics 199:675-681. https://doi.org/10.1534/genetics.114.173559.

Forutan, M., S. A. Mahyari, C. Baes, N. Melzer, F. S. Schenkel, and M. Sargolzaei. 2018. Inbreeding and runs of homozygosity before and after genomic selection in North American Holstein cattle. BMC Genomics 19:98. https://doi.org/10.1186/s12864-018-4453-z.

Granado-Tajada, I., S. T. Rodríguez-Ramilo, A. Legarra, and E. Ugarte. 2019. Consanguinidad y censo efectivo de población en la raza ovina de leche Latxa Cara Negra. Pages 405-407 in AIDA XVIII Jornadas de Producción Animal, Zaragoza, Spain.

Gutiérrez, J. P., I. Cervantes, and F. Goyache. 2009. Improving the estimation of realised effective population sizes in farm animals. J. Anim. Breed. Genet. 126:327-332. https://doi.org/10.1111/j.1439 $-0388.2009 .00810 . x$.

Gutiérrez, J. P., I. Cervantes, A. Molina, M. Valera, and F. Goyache. 2008. Individual increase in inbreeding allows estimating effective sizes from pedigrees. Genet. Sel. Evol. 40:359-378. https://doi .org/10.1186/1297-9686-40-4-359.

Gutiérrez, J. P., and F. Goyache. 2005. A note on ENDOG: A computer program for analysing pedigree information. J. Anim. Breed.
Genet. 122:172-176. https://doi.org/10.1111/j.1439-0388.2005 .00512.x.

Hammerly, S. C., D. A. de la Cerda, H. Bailey, and J. A. Johnson. 2016. A pedigree gone bad: Increased offspring survival after using DNA-based relatedness to minimize inbreeding in a captive population. Anim. Conserv. 19:296-303. https://doi.org/10.1111/ acv.12247.

Hill, W. G., and B. S. Weir. 2011. Variation in actual relationship as a consequence of Mendelian sampling and linkage. Genet. Res. (Camb.) 93:47-64. https://doi.org/10.1017/S0016672310000480.

Howard, J. T., J. E. Pryce, C. Baes, and C. Maltecca. 2017. Invited review: Inbreeding in the genomics era: Inbreeding, inbreeding depression, and management of genomic variability. J. Dairy Sci. 100:6009-6024. https://doi.org/10.3168/jds.2017-12787.

Kardos, M., G. Luikart, and F. W. Allendorf. 2015. Measuring individual inbreeding in the age of genomics: marker-based measures are better than pedigrees. Heredity 115:63-72. https://doi.org/10 $.1038 /$ hdy.2015.17.

Keller, M. C., P. M. Visscher, and M. E. Goddard. 2011. Quantification of inbreeding due to distant ancestors and its detection using dense single nucleotide polymorphism data. Genetics 189:237-249. https://doi.org/10.1534/genetics.111.130922.

Kijas, J. W., J. A. Lenstra, B. Hayes, S. Boitard, L. R. Porto Neto, M. San Cristobal, B. Servin, R. McCulloch, V. Whan, K. Gietzen, S. Paiva, W. Barendse, E. Ciani, H. Raadsma, J. McEwan, B. Dalrymple, and International Sheep Genomics Consortium. 2012. Genome-wide analysis of the world's sheep breeds reveals high levels of historic mixture and strong recent selection. PLoS Biol. 10:e1001258. https://doi.org/10.1371/journal.pbio.1001258.

Larroque, H., F. Barillet, G. Baloche, J. M. Astruc, D. Buisson, F. Shumbusho, V. Clément, G. Lagriffoul, I. Palhiere, R. Rupp, C. Carillier, C. Robert-Granié, and A. Legarra. 2014. Toward genomic breeding programs in French dairy sheep and goats. In Proceedings of the 10th World Congress of Genetics Applied to Livestock Production, Vancouver, Canada.

Legarra, A., G. Baloche, F. Barillet, J. M. Astruc, C. Soulas, X. Aguerre, F. Arrese, L. Mintegi, M. Lasarte, F. Maeztu, I. Beltrán de Heredia, and E. Ugarte. 2014. Within- and across-breed genomic predictions and genomic relationships for Western Pyrenees dairy sheep breeds Latxa, Manech, and Basco-Béarnaise. J. Dairy Sci. 97:3200-3212. https://doi.org/10.3168/jds.2013-7745.

Leroy, G., T. Mary-Huard, E. Verrier, S. Danvy, E. Charvolin, and C. Danchin-Burge. 2013. Methods to estimate effective population size using pedigree data: Examples in dog, sheep, cattle and horse. Genet. Sel. Evol. 45:1. https://doi.org/10.1186/1297-9686-45-1.

Li, C. C., and D. G. Horvitz. 1953. Some methods of estimating the inbreeding coefficient. Am. J. Hum. Genet. 5:107-117.

Li, M.-H., I. Strandén, T. Tiirikka, M.-L. Sevón-Aimonen, and J. Kantanen. 2011. A comparison of approaches to estimate the inbreeding coefficient and pairwise relatedness using genomic and pedigree data in a sheep population. PLoS One 6:e26256. https://doi .org/10.1371/journal.pone.0026256.

Malécot, G. 1948. Les Mathématiques de l'Hérédité. Masson \& Cie, Paris, France.

McQuillan, R., A. L. Leutenegger, R. Abdel-Rahman, C. S. Franklin, M. Pericic, L. Barac-Lauc, N. Smolej-Narancic, B. Janicijevic, O. Polasek, A. Tenesa, A. K. MacLeod, S. M. Farrington, P. Rudan, C. Hayward, V. Vitart, I. Rudan, S. H. Wild, M. G. Dunlop, A. F. Wright, H. Campbell, and J. F. Wilson. 2008. Runs of homozygosity in European populations. Am. J. Hum. Genet. 83:359-372. https://doi.org/10.1016/j.ajhg.2008.08.007.

Meuwissen, T. H., and Z. Luo. 1992. Computing inbreeding coefficients in large populations. Genet. Sel. Evol. 24:305-313. https:// doi.org/10.1186/1297-9686-24-4-305.

Misztal, I., S. Tsuruta, T. Strabel, B. Auvray, T. Druet, and D. H. Lee. 2002. BLUPF90 and related programs (BGF90). In Proceedings of the 7th World Congress on Genetics Applied to Livestock Production, Montpellier, France.

Nei, M. 1973. Analysis of gene diversity in subdivided populations. Proc. Natl. Acad. Sci. USA 70:3321-3323. https://doi.org/10 $.1073 /$ pnas. 70.12 .3321 . 
Oliehoek, P. A., and P. Bijma. 2009. Effects of pedigree errors on the efficiency of conservation decisions. Genet. Sel. Evol. 41:9. https:/ /doi.org/10.1186/1297-9686-41-9.

Peripolli, E., D. P. Munari, M. V. G. B. Silva, A. L. F. Lima, R. Irgang, and F. Baldi. 2017. Runs of homozygosity: Current knowledge and applications in livestock. Anim. Genet. 48:255-271. https://doi .org/10.1111/age.12526.

Pritchard, J. K., M. Stephens, and P. Donnelly. 2000. Inference of population structure using multilocus genotype data. Genetics 155:945-959.

Rodríguez-Ramilo, S. T., J. M. Elsen, and A. Legarra. 2019. Inbreeding and effective population size in French dairy sheep: comparison between genomic and pedigree estimates. J. Dairy Sci. 102:42274237. https://doi.org/10.3168/jds.2018-15405.

Rodríguez-Ramilo, S. T., J. Fernández, M. A. Toro, D. Hernández, and B. Villanueva. 2015. Genome-Wide estimates of coancestry, inbreeding and effective population size in the Spanish Holstein population. PLoS One 10:e0124157. https://doi.org/10.1371/ journal.pone. 0124157 .

Silió, L., M. C. Rodríguez, A. Fernández, C. Barragán, R. Benítez, C. Óvilo, and A. I. Fernández. 2013. Measuring inbreeding and inbreeding depression on pig growth from pedigree or SNP-derived metrics. J. Anim. Breed. Genet. 130:349-360. https://doi.org/10 $.1111 /$ jbg. 12031

Sonesson, A. K., J. A. Woolliams, and T. H. E. Meuwissen. 2012. Genomic selection requires genomic control of inbreeding. Genet. Sel. Evol. 44:27. https://doi.org/10.1186/1297-9686-44-27.

Toro, M. A., L. A. García-Cortés, and A. Legarra. 2011. A note on the rationale for estimating genealogical coancestry from molecular markers. Genet. Sel. Evol. 43:1-10. https://doi.org/10.1186/ 1297-9686-43-27.
Ugarte, E. 2007. The breeding program of Latxa breed. Biotechnol. Anim. Husb. 23:97-111. https://doi.org/10.2298/BAH0701097U.

Ugarte, E., and A. Legarra. 2003. Scientific background of the selection program in the Latxa breed. In: Breeding programmes for improving the quality and safety of products. New traits, tools, rules and organization? Zaragoza: D. Gabiña and S. Sanna, ed. CIHEAM, 2003. Pages 91-98 in Options Méditerranéennes: Série A. Séminaires Méditerranéens; n. 55. Meeting of the Sub-Network on Genetic Resources of the FAO-CIHEAM Inter-Regional Cooperative Research and Development Network on Sheep and Goats, Sassari, Italy.

Ugarte, E., E. Urarte, F. Arrese, J. Arranz, L. Silio, and C. Rodríguez. 1996. Genetic parameters and trends for milk production of blondfaced Latxa sheep using Bayesian analysis. J. Dairy Sci. 79:22682277. https://doi.org/10.3168/jds.S0022-0302(96)76604-3.

VanRaden, P. M. 1992. Accounting for inbreeding and crossbreeding in genetic evaluation of large populations. J. Dairy Sci. 75:3136-3144. https://doi.org/10.3168/jds.S0022-0302(92)78077-1.

VanRaden, P. M. 2008. Efficient methods to compute genomic predictions. J. Dairy Sci. 91:4414-4423. https://doi.org/10.3168/jds .2007-0980.

\section{ORCIDS}

I. Granado-Tajada (ㄱ https://orcid.org/0000-0002-6557-1467

S. T. Rodríguez-Ramilo @ https://orcid.org/0000-0001-7150-0692

A. Legarra (ㄴ) https://orcid.org/0000-0001-8893-7620

E. Ugarte $\odot$ https://orcid.org/0000-0002-2231-150X 